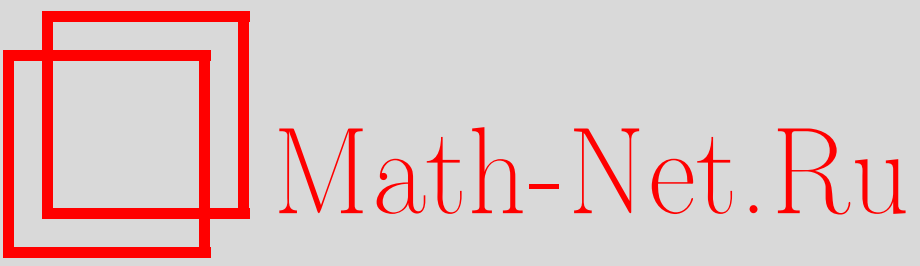

М. В. Хатунцева, Информация об одиннадцатой Колмогоровской студенческой олимпиаде по теории вероятностей, Теория вероятн. и ее примен., 2012, том 57, выпуск 4, 825

DOI: https://doi.org/10.4213/tvp4488

Использование Общероссийского математического портала Math-Net.Ru подразумевает, что вы прочитали и согласны с пользовательским соглашением

http: //www . mathnet.ru/rus/agreement

Параметры загрузки :

IP : 52.87 .193 .239

26 апреля 2023 г., 14:45:53 


\section{ИНФОРМАЦИЯ ОБ ОДИННАДЦАТОЙ КОЛМОГОРОВСКОЙ СТУДЕНЧЕСКОЙ ОЛИМПИАДЕ ПО ТЕОРИИ ВЕРОЯТНОСТЕЙ}

В ознаменование дня рождения А.Н. Колмогорова кафедра теории вероятностей механико-математического факультета Московского государственного университета им. М.В.Ломоносова при поддержке Московской государственной академии тонкой химической технологии им. М.В. Ломоносова провела одиннадцатую Колмогоровскую студенческую олимпиаду по теории вероятностей. Информацию о предыдущих олимпиадах можно найти на сайте кафедры теории вероятностей (http://mech.math.msu.su/probab), а также во втором выпуске журнала «Теория вероятностей и ее применения» за 2011 год.

Олимпиада была проведена 21 апреля 2012 г. раздельно для I-II и III-V курсов (продолжительность - 5 часов). В олимпиаде приняли участие и сдали работы 35 студентов I-II курсов и 21 студент III-V курсов механико-математического факультета Московского государственного университета, а также математикомеханического факультета Санкт-Петербургского государственного университета, факультета прикладной математики и компьютерных технологий Вологодского государственного педагогического университета и физико-технического факультета Киевского политехнического института.

\section{Задачи олимпиады}

В скобках после номера задачи (или пункта задачи) указываются курсы, на которых предлагалась данная задача, затем число решивших ее студентов I-II курсов и, наконец, число решивших ее студентов III-V курсов (для задач, которые предлагались только в одной возрастной группе, приведено только число решивших).

Задача 1. (I-V; 10, 6) Пусть $f:[0,1] \rightarrow \mathbf{R}-$ непрерывная функция, а $X_{1}, X_{2}, \ldots$ - н.о.р. случайные величины, равномерно распределенные на отрезке $[0,1]$. Вектор $\left(X_{(1)}, \ldots, X_{(n)}\right)$ - это значения случайных величин $X_{1}, \ldots, X_{n}$, упорядоченные по возрастанию. Доказать, что $\sum_{i=1}^{n} f\left(X_{(i)}\right)\left(X_{(i)}-X_{(i-1)}\right) \rightarrow \int_{0}^{1} d(x) d x$ при $n \rightarrow \infty$ с вероятностью единица (здесь $X_{(0)}:=0$ ).

Задача 2. (I-V; 14, 6) Летящий в пространстве по случайной прямой метеорит, сталкивается с неподвижной шарообразной планетой. Точка пересечения указанной прямой с перпендикулярным ей центральным сечением планеты равномерно распределена на этом сечении. Найти математическое ожидание угла падения.

Задача 3. Пусть $X$ - интегрируемая случайная величина и $\varphi(x)=\mathbf{E}|X-x|$, $x \in \mathbf{R}$. Верно ли, что функция $\varphi$ однозначно определяет распределение $X$, если a) (I-II; 10) $X$ имеет непрерывную плотность, б) (III-V; 4) $X$ не обязательно имеет непрерывную плотность.

Задача 4. (I-V; 7,4$)$ Случайным образом выбирается перестановка $n$ элементов. Найти математическое ожидание суммы квадратов длин ее циклов.

Задача 5. (I-V; 2,4$)$ Пусть $S_{0}=0$ и $S_{n}=\sum_{i=1}^{n} X_{i}, n \in \mathbf{N}$, где н.о.р. случайные величины $\left\{X_{i}, i \in \mathbf{N}\right\}$ принимают значения 1 и -1 с вероятностями $p$ и $q$ и $p<q$. Доказать, что $\mathbf{E}\left(\sup _{n>0} S_{n}\right)^{2}<\infty$.

Задача 6. (III-V; 6) Пусть $\left\{M_{n}, n \geqslant 0\right\}$ - неотрицательный мартингал. Доказать, что, попав в нуль, он с вероятностью единица из него не выйдет (т.е. $\left.\mathbf{P}\left(\bigcup_{k<n}\left\{M_{k}=0, M_{n}>0\right\}\right)=0\right)$.

Задача 7. (I-V; 1,2$)$ Для каждого $n \in \mathbf{N}$ пусть $X_{1}^{(n)}, \ldots, X_{n+1}^{(n)}$ - н.о.p. случайные величины, принимающие с равными вероятностями значения $1, \ldots, n$. Пусть $\tau_{n}$ - это первый номер $i \in\{2, \ldots, n+1\}$, для которого в наборе $\left\{X_{1}^{(n)}, \ldots, X_{i}^{(n)}\right\}$ присутствуют хотя бы два совпадающих значения. Доказать, что последовательность $\tau_{n} / \sqrt{n}$ сходится по распределению к некоторой случайной величине $Y$, и найти ее плотность. 